\title{
Housing preferences during the pandemic: effect on home price, rent, and inflation measurement
}

\author{
Molly Boesel ${ }^{1} \cdot$ Shu Chen ${ }^{1} \cdot$ Frank E. Nothaft ${ }^{1}$ (]
}

Published online: 18 October 2021

(c) National Association for Business Economics 2021

\begin{abstract}
With shelter comprising a one-third weight in the Consumer Price Index, an accurate measure of rent change is essential for determining factors affecting inflation measurement, economic policy, and consumer and business decisions. The pandemic led to a shift in consumer demand for more residential space, both in the home's interior and exterior. With remote work severing the need to be located near the place of employment, some households opted for more space in lower-density areas, moving out of high-rise structures in the urban core to suburban and exurban single-family and low-rise homes, altering the price and rent-growth patterns among single-family detached, attached, and multifamily properties. While measures of rent change are available for multifamily residential properties, none exist for the single-family rental market, which makes up one-half of the residential rental market. The CoreLogic Single-Family Rent Index (SFRI) fills the gap in rent measurement. The SFRI is a repeat-transaction rent index for single-family homes and is available monthly for the U.S., by major metros, by rent price tier and by property type. The SFRI reveals that after 12 months of the pandemic annual rent growth for detached properties was more than 5 percentage points higher than for attached properties. Substituting the SFRI for Owners' Equivalent Rent, we find that Core CPI inflation would be nearly 2 percentage points higher by mid-2021. To the extent the rapid acceleration in single-family detached rent growth has yet to be reflected in the CPI, inflation measurement will be understated with delayed signals for economic policy makers.
\end{abstract}

Keywords Rent index $\cdot$ Multiple listing service $\cdot$ Consumer price index

JEL Classification E31 $\cdot \mathrm{R} 31 \cdot \mathrm{R} 32$

The COVID-19 pandemic has had widespread effects on households. Remote work has eliminated the need for many employees to commute to their employers and increased the need for home offices. Families with school-age children had to find room for an in-home classroom. Many households wanted to move to neighborhoods and structures with lower population density. Changes such as these have altered the

Winner of NABE's 2021 Edmund A. Mennis Contributed Paper Award.

Molly Boesel

mboesel@corelogic.com

Shu Chen

shchen@corelogic.com

Frank E. Nothaft

fnothaft@corelogic.com

1 CoreLogic, Irvine, USA amount of living space a family prefers within and outside their home, and the type of community they live in. This has had a pronounced effect on the valuation of housing.

Changes in shelter costs affect inflation measurement. Rent comprised $32 \%$ of the U.S. city average of the Consumer Price Index for all urban consumers (CPI-U) this past year. Of this, $8 \%$ reflected tenant rent on their primary residence and $24 \%$ was an imputed estimate of rent for owneroccupied homes, known as Owners' Equivalent Rent (OER). The large weight assigned to OER underscores the need for accurate measurement of imputed rent for owner-occupied homes. Just prior to the pandemic, $84 \%$ of owner-occupied homes were 1-unit detached houses, 5\% were 1-unit attached homes (primarily townhomes and rowhouses) and $4 \%$ were condominiums/cooperatives in multi-unit buildings. ${ }^{1}$

${ }_{1}^{1}$ U.S. Census Bureau, 2019 American Housing Survey for the United States (https://www.census.gov/programs-surveys/ahs/data/inter active/ahstablecreator.html?s_areas $=00000 \&$ s_year $=2019 \&$ s_table 
How much have residential rents risen in recent years, especially under the impact of pandemic, and how do these rent increases compare across different geographic markets, price tiers and property types? Measurement of rental price growth has the same methodological issues as calculations of house price growth. For example, median rent measures do not control for quality, while the quality or mix of properties rented will change from period to period. Therefore, such a measurement reflects changes in the housing stock that is rented as well as the trend in rent levels within the market, but the two components cannot easily be decomposed. Other methods of measuring prices, such as hedonic price models, are data intensive, requiring detailed information on the characteristics of the property.

Other methods of measuring rental price growth have been used that collect rent on the same dwellings over time to produce measures of rent growth. The most well-known publicly available index is from the Bureau of Labor Statistics' (BLS) Consumer Price Index (CPI), and relies on semiannual surveys of rental dwellings to construct a rental index at the national level, for census regions, and for some metropolitan areas. An ideal measure of price change would measure the market rent paid by new tenants, rather than the market rent of all tenants, which would give a measure of changes to the current leasing market. A weakness in a measure including all tenants is that it would be slow to reflect changing market conditions. In addition, rental prices should be measured for single-family and multifamily homes separately. A single-family rent measure would capture the significant differences in this structure type, would more closely approximate owner-occupied housing, and could be an improvement over OER for use in the CPI, as suggested by Ozimek (2016).

To control for the constant quality issue, Ambrose et al. (2015) constructed a repeat rent index utilizing repeat pairing. Repeat pairing solves measurement issues that impact price measurement. Ambrose, Coulson and Yoshida compared their indexes for 11 MSAs with the CPI indexes. They found the number of cities and years for which rents fell is substantial and more than the CPI data indicates, particularly after the housing crisis in 2007.

As an extension of Ambrose et al. (2015), we estimate repeat rent indexes for single-family rentals for 101 corebased statistical areas (CBSAs), create four indexes by rent tier, two indexes by property type for CBSAs with more than 100 repeat pairs a month, and create a national index from a weighted average of the top 47 CBSA indexes. Indexes by property type provide insight on the rent-growth divergence

\footnotetext{
Footnote 1 (continued)

name $=$ TABLE1\&s_bygroup $1=2 \&$ s_bygroup $2=3 \&$ s_filtergroup $1=$ $2 \&$ s_filtergroup $2=1)$. Of the remaining owner-occupied homes, $6 \%$ were mobile/manufactured homes and $1 \%$ were in 2 - to 4 -unit houses.
}

in detached homes and attached homes under the impact of pandemic. Indexes by rent tier provide insight on whether lower-rent homes have had faster rent growth than higherrent homes; the Joint Center for Housing Studies (2016) has concluded that the supply of lower-rent homes has declined, adding rent-growth pressure to the lower-end market. As our data are for single-family houses, townhouses and condominium rentals only, a measure such as the SFRI could substitute for the owner-equivalent rent measure that makes up $24 \%$ of the Consumer Price Index.

\section{Data}

We use CoreLogic multiple listing service (MLS) data and repeat-pairing methodology to create the single-family rent index (SFRI). CoreLogic MLS data were obtained from 184 local REALTOR $®$ member associations (or boards) across the country. MLS rental data contains listing ID, listing status, listing date, listing rent, rented date, rent amount, property address and other property characteristics. Rent records starting in the late 1990s were used to create the SFRI. The rental listings include attached or detached single-family houses and condominiums and exclude multifamily rental apartment buildings.

Since MLS boards are independent, each MLS board has a different date that they start to collect the rental data. Different MLS boards might cover the same counties or zip codes. After removing duplicates and selecting CBSAs with data available no later than 2010 , there were 47 CBSAs that have enough data to create four price tiers. ${ }^{2}$ Of these, 44 are in the top 100 CBSAs ranked by 2014 population (Fig. 1). ${ }^{3}$

Table 1 shows the distribution of the time between repeat pairs. The median time between new tenants was between one and two years, which reflects the typical lease term of one year. In $90 \%$ of the repeat pairs, the second rent pair is within 5 years, consistent with the distribution reported by Deng et al. (2003). ${ }^{4}$

\footnotetext{
${ }^{2}$ Some data exclusions were used to screen for invalid rents and vacation or other short-term rentals. To exclude invalid rent amounts that were entered by the agents by mistake, all the listings with monthly rent less than $\$ 100$ or more than $\$ 10,000$ were excluded. For each CBSA, matched pairs with annual rent growth at or below the first percentile or at or above the 99th percentile of the rent-growth distribution were removed. Properties that were rented more than twice per year on average were considered vacation or short-term rentals and were excluded.

${ }^{3}$ Population is based on annual estimates from the Census Bureau's Population Estimates Program (PEP).

${ }^{4}$ Deng, Gabriel and Nothaft (2003) calculated the length of tenant occupancy using BLS data from 1987-1998 and reported that $89 \%$ of the rental housing stock had length of tenant occupancy of no more than 5 years.
} 
Fig. 1 CBSAs covered by the SFRI: 47 with multiple tiers, 54 with one tier

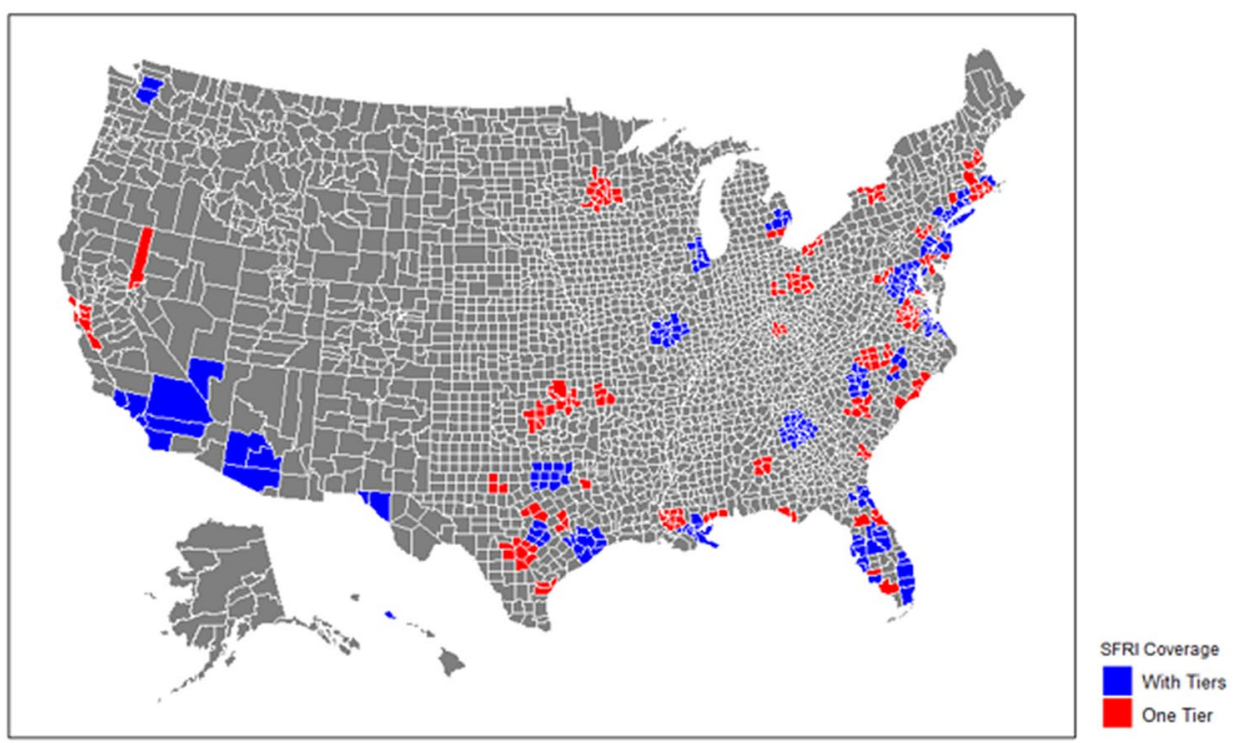

Table 1 Distribution of time between repeat pairs

\begin{tabular}{lcl}
\hline Time & Percentage & $\begin{array}{l}\text { Cumulative } \\
\text { percentage }\end{array}$ \\
\hline $0<$ months $\leq 6$ & 4.2 & 4.2 \\
$6<$ months $\leq 12$ & 14.4 & 18.6 \\
$1<$ years $\leq 2$ & 37.3 & 55.9 \\
$2<$ years $\leq 3$ & 18.6 & 74.5 \\
$3<$ years $\leq 4$ & 9.7 & 84.2 \\
$4<$ years $\leq 5$ & 5.5 & 89.7 \\
Years $>5$ & 10.3 & 100 \\
\hline
\end{tabular}

The national index is the weighted average of 47 CBSAs' indexes that have an uninterrupted time series. ${ }^{5}$ The weight for each CBSA is based on the aggregate value of the rental stock, which is calculated as the median contract rent multiplied by rental stock from the 2010 5-year estimate of the American Community Survey (ACS). ${ }^{6}$ For these 47 CBSAs, Table 2 shows their rank by population, their weight in the national index, and the 2010 median contract rent from our MLS data and from ACS. One feature of the MLS data might be that it disproportionately includes higher-rent homes. While the ACS data include multifamily rental apartments, and single-family rental homes typically will have more amenities and living space, the comparison suggests that the lower-rent single-family segment may be underrepresented in the MLS.

\footnotetext{
${ }^{5}$ For the national index time series, 18 CBSAs begin in 2004, 19 begin from 2005 to 2007, and 10 begin from 2008 to 2010 .

6 The rental stock includes occupied rental units, vacant-for-rent, and vacant-rented.
}

\section{Empirical approach}

The methodology used in this paper is repeat sales, which is widely used for house prices and is here applied to rental prices. The specific method used in this paper was proposed by Shiller (1991) as a reformulation of prior methods detailed by Bailey et al. (1963) and Case and Shiller (1987). The Shiller method avoids the need for exponentiation of the regression index results and therefore maintains an arithmetic formulation. Further details on the repeat sales methodology can be found in the "Appendix".

Repeat pairs are created by matching the property address of rented properties across multiple rented dates. A pair is created by two consecutive rent records for the same rental property. For example, we create two repeat pairs from a property that was rented three times since 2005 . A pair is created by the records from the first time and the second time it was rented; the other pair is created by the records from the second time and the third time it was rented. The rented date and rent amount were modeled for the rental index creation.

Four price tiers are created by the median rent in each CBSA, where the median was calculated from the data used for the SFRI. The low tier (tier 1) is $75 \%$ or less of the median rent, the low-to-middle tier (tier 2) is more than $75 \%$ and up to $100 \%$ of the median rent, the middle-to-moderate tier (tier 3) is more than $100 \%$ and up to $125 \%$ of the median rent and the high tier (tier 4 ) is greater than $125 \%$ of the median rent.

Two property type tiers are created from detached homes and attached homes. The detached tier is defined as properties with a free-standing residential building, and the attached tier is defined as a single-family dwelling that is 
Table 2 Weights and median rent

$$
\text { CBSA }
$$

Population rank

New York-Jersey City-White Plains, NY-NJ

Los Angeles-Long Beach-Glendale, CA

Chicago-Naperville-Arlington Heights, IL

Houston-The Woodlands-Sugar Land, TX

Atlanta-Sandy Springs-Roswell, GA

Washington-Arlington-Alexandria, DC-VA-MD-WV

Dallas-Plano-Irving, TX

Riverside-San Bernardino-Ontario, CA

Phoenix-Mesa-Scottsdale, AZ

San Diego-Carlsbad, CA

Anaheim-Santa Ana-Irvine, CA

Nassau County-Suffolk County, NY

Tampa-St. Petersburg-Clearwater, FL

St. Louis, MO-IL

Baltimore-Columbia-Towson, MD

Seattle-Bellevue-Everett, WA

Miami-Miami Beach-Kendall, FL

Warren-Troy-Farmington Hills, MI

Charlotte-Concord-Gastonia, NC-SC

Fort Worth-Arlington, TX

Orlando-Kissimmee-Sanford, FL

Philadelphia, PA

Las Vegas-Henderson-Paradise, NV

Montgomery County-Bucks County-Chester County, PA

Boston, MA

Austin-Round Rock, TX

Fort Lauderdale-Pompano Beach-Deerfield Beach, FL

Virginia Beach-Norfolk-Newport News, VA-NC

Jacksonville, FL

West Palm Beach-Boca Raton-Delray Beach, FL

Camden, NJ

Silver Spring-Frederick-Rockville, MD

New Orleans-Metairie, LA

Hartford-West Hartford-East Hartford, CT

Raleigh, NC

Tucson, AZ

Urban Honolulu, HI

Bridgeport-Stamford-Norwalk, CT

Lake County-Kenosha County, IL-WI

New Haven-Milford, CT

Oxnard-Thousand Oaks-Ventura, CA

El Paso, TX

North Port-Sarasota-Bradenton, FL

Cape Coral-Fort Myers, FL

Lakeland-Winter Haven, FL

Port St. Lucie, FL

Fayetteville, NC
Weight

MLS
$(\$)$

0.064

0.122

0.067

0.039

0.036

0.049

0.030

0.029

0.030

0.040

0.038

0.016

0.020

0.014

0.021

0.026

0.023

0.012

0.012

0.014

0.021

0.013

0.022

0.012

0.047

0.014

0.016

0.014

0.010

0.010

0.007

0.012

0.008

0.010

0.012

0.007

0.011

0.007

0.004

0.007

0.008

0.004

0.006

0.006

0.003

0.003

0.003

\section{0}

2400

1550

1250

1285

1750

1300

1575

1095

2250

2300

1913

1100

1300

1650

1650

1500

1150

1075

1200

1050

1500

1100

1600

1950

1200

1300

1300

1100

1350

1500

1850

1200

1300

1195

1050

1700

1730

1550

1300

2000

1095

1200

950

950

1000

875
ACS contract rent (\$) 1089 1017 787 662 747 1173 683 954 777 1155 1344 1291 755 569 844 893 877 697 604 705 835 740 882 979 1001 745 986 803 746 975 824 1253 733 772 668 630 1197 1021 790 823 1294 520 825 811 641 842 609 
Fig. 2 CoreLogic HPI and SFRI

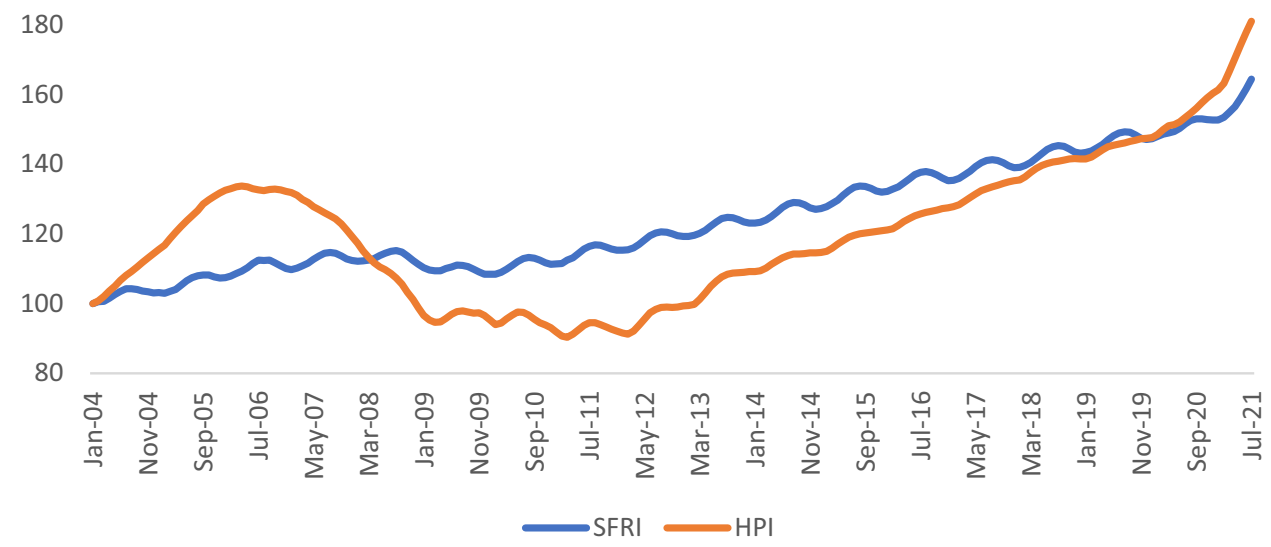

attached to other single-family dwellings, which includes duplexes, triplexes, quadplexes, townhouses, rowhouses, condos and co-ops.

\section{Results}

The resulting national SFRI has several notable features (Fig. 2). First, it exhibits a strong seasonal effect, with rent changes generally higher in the summer and lower in the winter. Second, rents fell during the Great Recession as household formations slowed and housing demand weakened. Third, rent in the single-family rental market rebounded from the Great Recession by 2011, a full 6 years earlier than sales prices in the home sale market. Fourth, rents initially weakened during the early months of the COVID-19 pandemic, but then strengthened during the pandemic as housing demand increased amid a shortage of inventory, similar to features noted by Kuk (2021).

\subsection{SFRI as an inflation measure}

The BLS uses survey data to measure the shelter portion of the CPI (Bureau of Labor Statistics 2009). Two major components of the shelter index are rent of primary residence and Owner's Equivalent Rent (OER), which make up $8 \%$ and $24 \%$ of the CPI, respectively. ${ }^{7}$ These two components make up an even larger weight in the Core CPI: $10 \%$ and $30 \%$, respectively, as of December 2020. The BLS rent of primary residence measure in the CPI is collected from data on all current tenants, not just new tenants. In

\footnotetext{
7 The weights for rent of primary residence and OER vary slightly from 2005 to 2021 , ranging from $5.8 \%$ to $7.9 \%$ for rent of primary residence and $23.4 \%$ to $25.2 \%$ for OER.
}

addition, owner-occupied housing expenses in the CPI are measured as the implicit rent that owner occupants would have to pay if they were renting their homes, referred to as OER. Because rental homes have a lease that generally holds monthly rent constant for a period of time, that means that the CPI rent measures will catch changes in market conditions with a lag and will also tend to be smoother over time. Bernstein et al. (2021) find that increases in the CoreLogic Case-Shiller index filter into the CPI shelter component with a lag of 16 months since 2000. Crone et al. (2006) have shown that rent change may be underestimated when a property does not change tenancy. A lag of approximately 1 year is evident in a comparison of the 12-month percent change in the SFRI and CPI rent metrics (Fig. 3). An alternative measure for the owner-occupied portion of the shelter index could substitute the SFRI for the OER as the SFRI would closely approximate current rental price changes in owneroccupied housing.

When the SFRI is substituted for the OER, we see two time periods of interest for the Core CPI (Fig. 4). First, the core CPI measure using the SFRI shows inflation beginning to fall in late 2008 and dropping below $1 \%$ in December 2008. In comparison, the BLS core CPI measure did not begin to fall until late 2009 and the fall below $1 \%$ did not occur until April 2010. Second, during the pandemic, the core CPI measure using the SFRI reached 2\% in September 2020, a full seven months earlier than the BLS core CPI. In addition, the core CPI with SFRI shows inflation a full percentage point above the BLS measure (Fig. 5). The implications for these two time periods are clear. In the first instance, inflation appeared to be stable during the Great Recession, when instead it was falling. In the second instance, one can see that there was an early signal that higher inflation was emerging.

Another important U.S. inflation measure uses imputed rent as well. The Bureau of Economic Analysis (BEA) 
Fig. 3 Year-over-year percent change of CPI and SFRI

Fig. 4 New measure of core inflation

Year-over-year Percent Change of CPI and SFRI

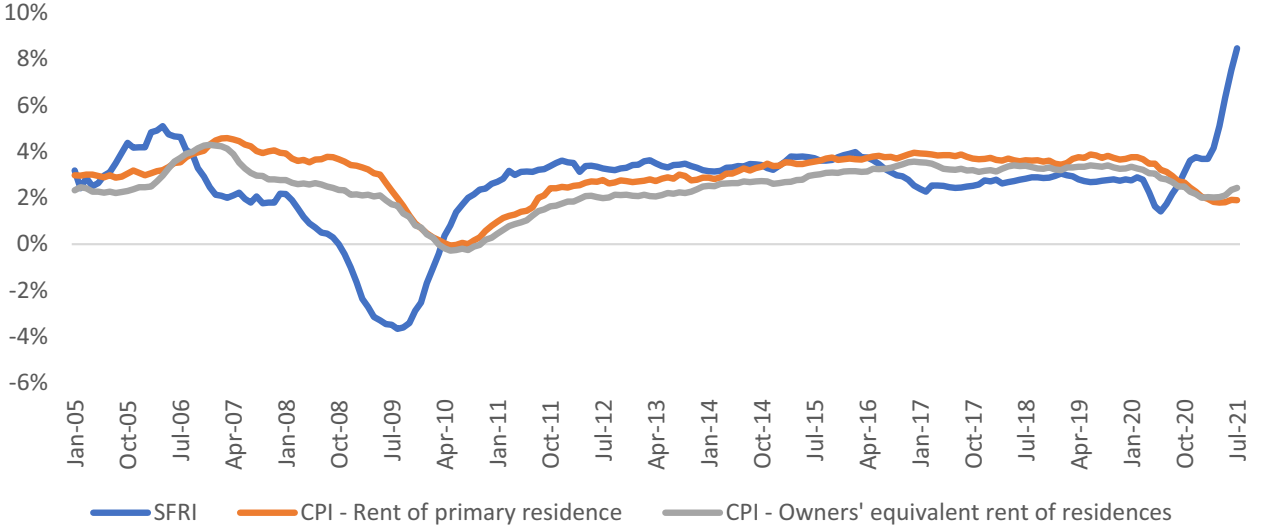

New Measure of Core Inflation

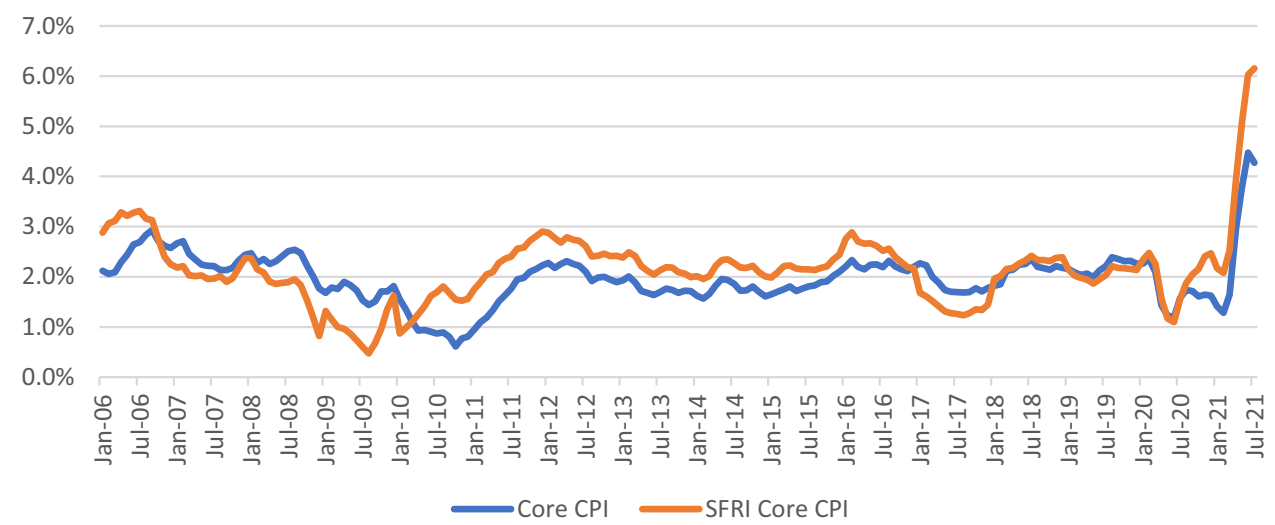

New Measure Shows Core CPI Hitting 2\% Seven Months Earlier (September 2020)

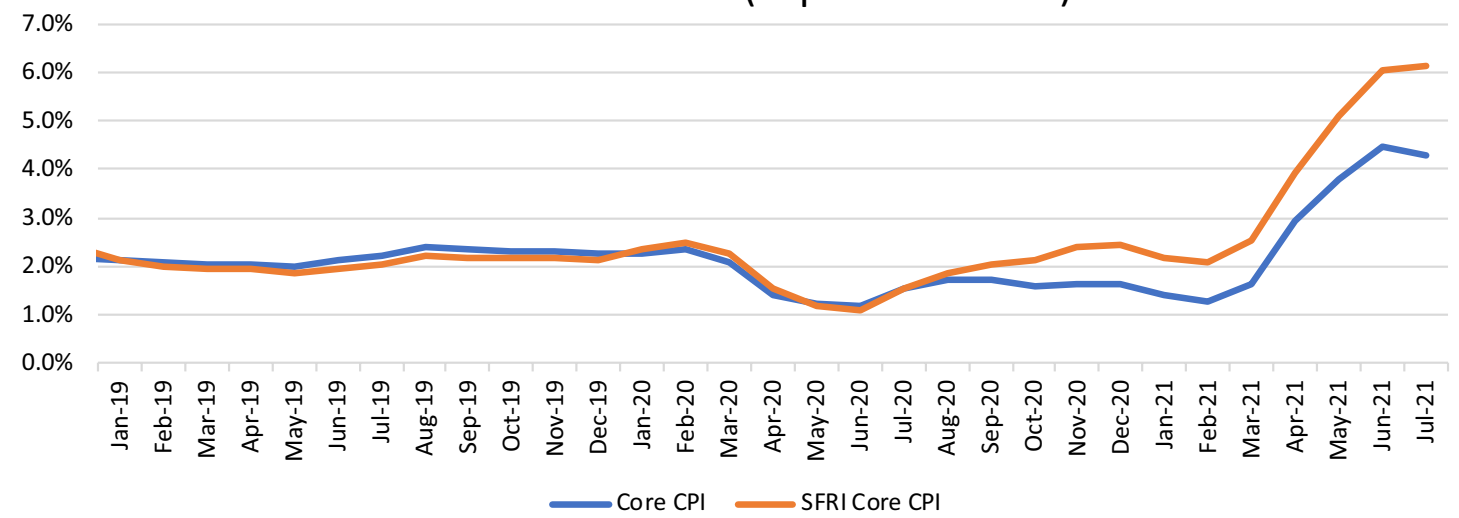

Fig. 5 New measure shows core CPI hitting 2\% 7 months earlier (September 2020) 
Fig. 6 SFRI year-over-year percent change by property type

\section{SFRI Year-over-year Percent Change By Property Type}

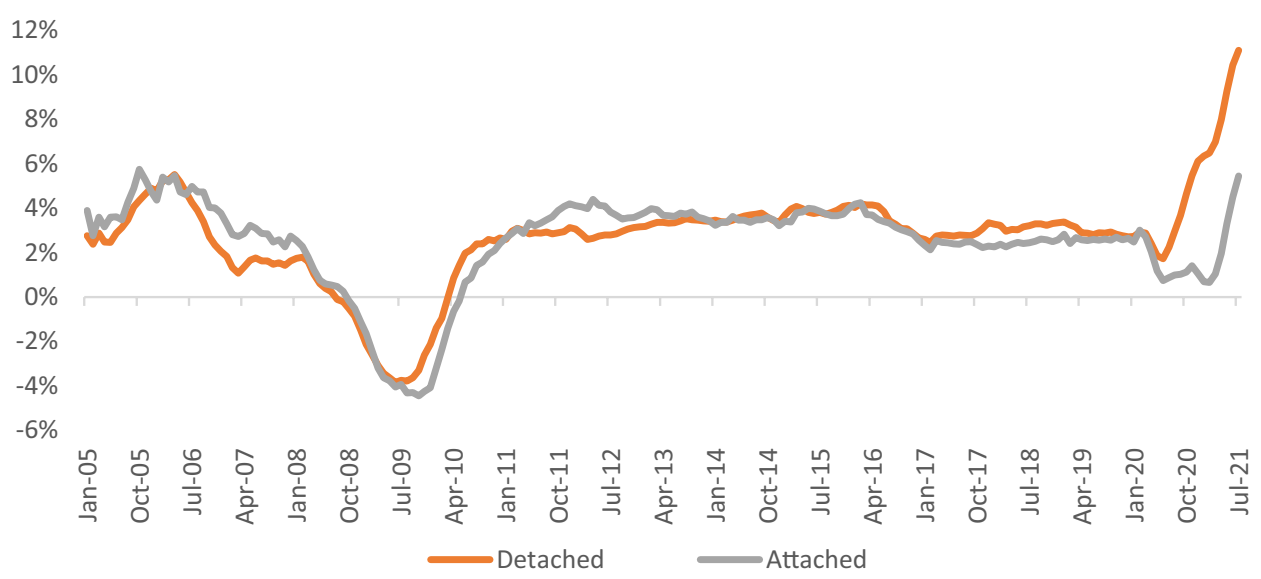

imputes a value for owner-occupied homes in the NIPA Personal Consumption Expenditure $(\mathrm{PCE})^{8}$ - the core PCE price index is one of the metrics used by the Federal Reserve when making monetary policy decisions. To compute imputed rent on owner-occupied stationary housing, the BEA uses survey data, including the decennial census, the American Housing Survey, the Current Population Survey, and the CPI OER (Bureau of Economic Analysis 2020). Comparing year-over-year change in the BEA imputed rent measure to the SFRI starting in 2020, we see that the BEA measure slows from 3.3\% in Q1 2020 to 2.2\% in Q2 2021, while the SFRI shows single-family rent growth increasing from 2.8\% in Q1 2020 to 6.3\% in Q2 2021. This result suggests that the core PCE understates inflation in the same manner as core CPI during the past year.

\subsection{Differences by property type and price tier}

The pandemic affected working populations differently, generally with higher-wage workers having the option to work from home, and lower-wage workers experiencing sharp decreases in their income as their place of business shut down or restricted employee capacity. The SFRI was quick to show differences in rent growth by property type and by rent price tier.

Results for the SFRI by property type (Fig. 6) suggest that a shift in consumer demand during the pandemic for more residential space, both in the home's interior and exterior, and to communities with lower population density led to higher rent increases for detached houses. Prior to the pandemic, and for much of the SFRI series, rent grew at similar rates for detached and attached properties. However, a clear

\footnotetext{
8 The imputed rent on owner-occupied stationary housing had a weight of $14 \%$ for the 2020 core PCE.
}

separation in rent growth emerged after the pandemic began with rents rising the most for single-family detached and least for multi-unit rental homes. Comparing rent growth from the second quarter of 2020 to the second quarter of 2021, single-family detached rental houses experienced 9.2\% growth, single-family attached rental homes were up $3.3 \%$, while high-rise rental apartment houses experienced a $2.4 \%$ decline in effective rent. Furthermore, rental vacancy rates on one-family homes declined during 2020 but rose on multifamily rental. ${ }^{9}$ The demand for additional space from remote workers is cited by Stanton (2021) and points to potential construction design changes if remote work remains highly utilized. Rappaport (2021) posits that the potential for a remote-office hybrid work model to become permanent could result in employees living further from their places of employment. This reallocation away from the city center (where rental housing is denser) is discussed in Ramani (2021) and has implications for businesses relying on consumption by higher-wage workers who generally had a work-for-home option during the pandemic.

The uneven economic recovery is reflected in rent price changes by price tier (Fig. 7). From 2014 to early 2020, rents in the high-price tier grew more slowly than those in the low-price tier. However, in autumn 2020, rent growth for higher-priced properties accelerated, reaching the highest growth recorded in the series, while rents for the lowest price tier were sluggish to recover. Homes with higher rent have, on average, more interior living space and a larger lot size, property attributes that were in demand during the

\footnotetext{
${ }^{9}$ Multifamily effective rent change was from Moody's Analytics $\mathrm{CRE}$ and is based on rental buildings with at least 40 units (minimum of 20 units in California). The Census Bureau CPS/HVS reported that rental vacancy rates between the second quarter of 2020 and second quarter of 2021 declined 0.5 percentage points for 1-unit structures and rose 1.1 percentage points for buildings with 5 or more units.
} 
Fig. 7 Year-over-year rent growth by price tiers

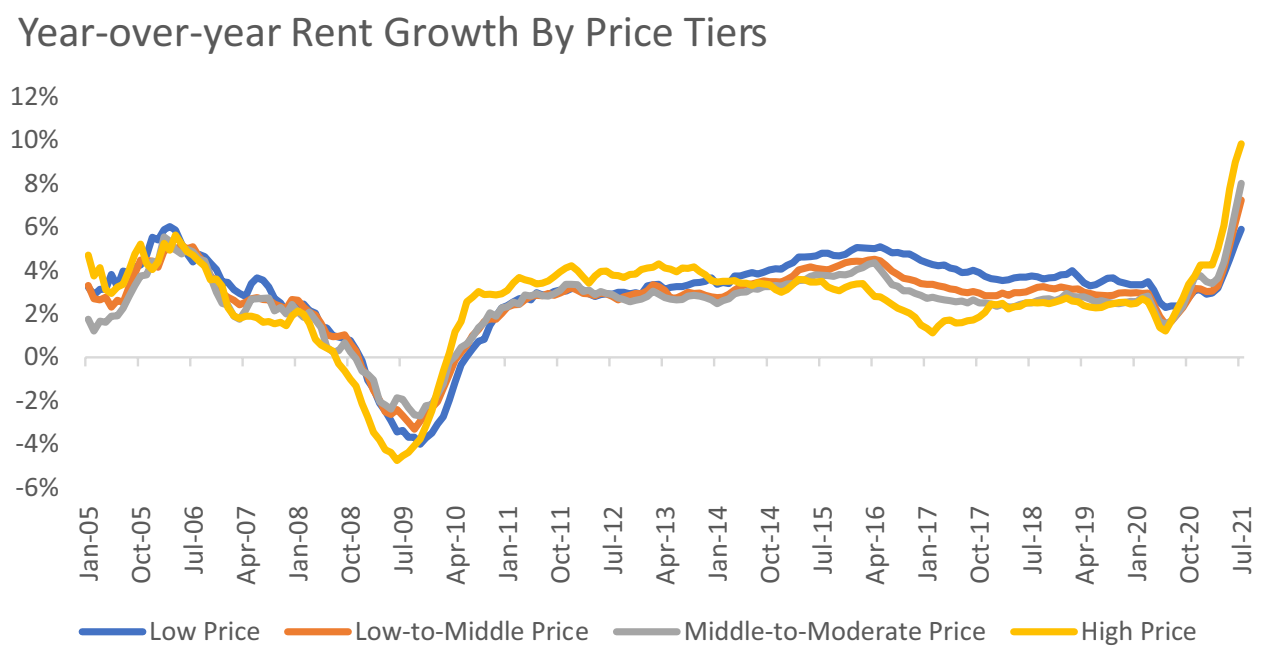

Phoenix CPI

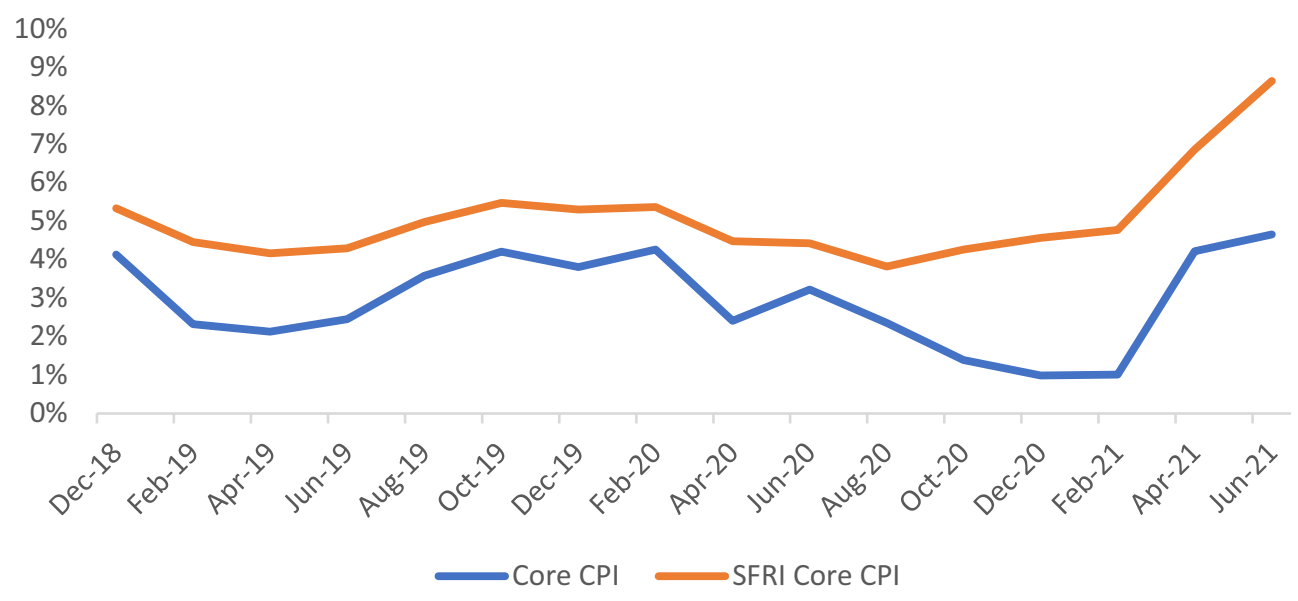

Fig. 8 Phoenix CPI

pandemic. Tracking rent growth at different price levels could be important for policies targeting different rental populations.

\subsection{Metro-level results}

The SFRI is modeled for 101 CBSAs, 47 of which have detailed price tier indices and 88 of which have property type tiers. This section identifies select metro areas for which the SFRI would enhance the measurement of inflation, show the effect of a natural hazard event on housing cost, and reveal structure and location preference during the pandemic.

As with the national index, inflation appears to be mismeasured in metro areas. Of the 101 CBSAs modeled using the MLS data, 21 had BLS rental indices that could be used for comparison, and we show two examples here. Using the same method of replacing the OER with the SFRI, both Houston and Phoenix exhibit inflation earlier and higher using the SFRI in place of the OER. In the case of Houston, the SFRI core CPI experiences turning points sooner than the BLS core CPI. Phoenix stands out in the CoreLogic SFRI as having the highest rent growth since 2019, and by July 2021, rents there were increasing $19 \%$ year over year, more than double the rate of the national index. Because the SFRI finds single-family rent growth to be much more rapid, the SFRI-adjusted core CPI for Phoenix shows annual inflation running 2 to 4 percentage points faster than reported by BLS since October 2020 (Figs. 8, 9). ${ }^{10}$

\footnotetext{
10 The BLS CPI series for Phoenix begins in 2018, therefore we are unable to compare core inflation for this metro during the Great Recession, but the pandemic period shows that the SFRI core CPI rises sooner and higher than the BLS core CPI.
} 
Fig. 9 Houston CPI

\section{Houston CPI}

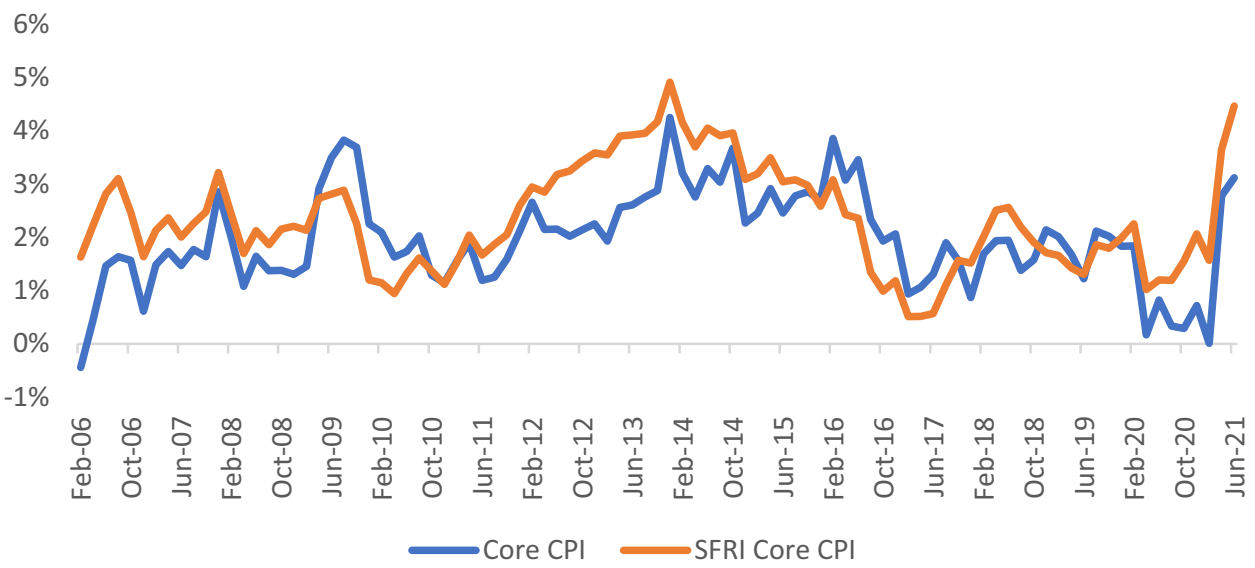

Fig. 10 Houston SFRI Before and After Hurricane Harvey

Houston SFRI Before and After Hurricane Harvey

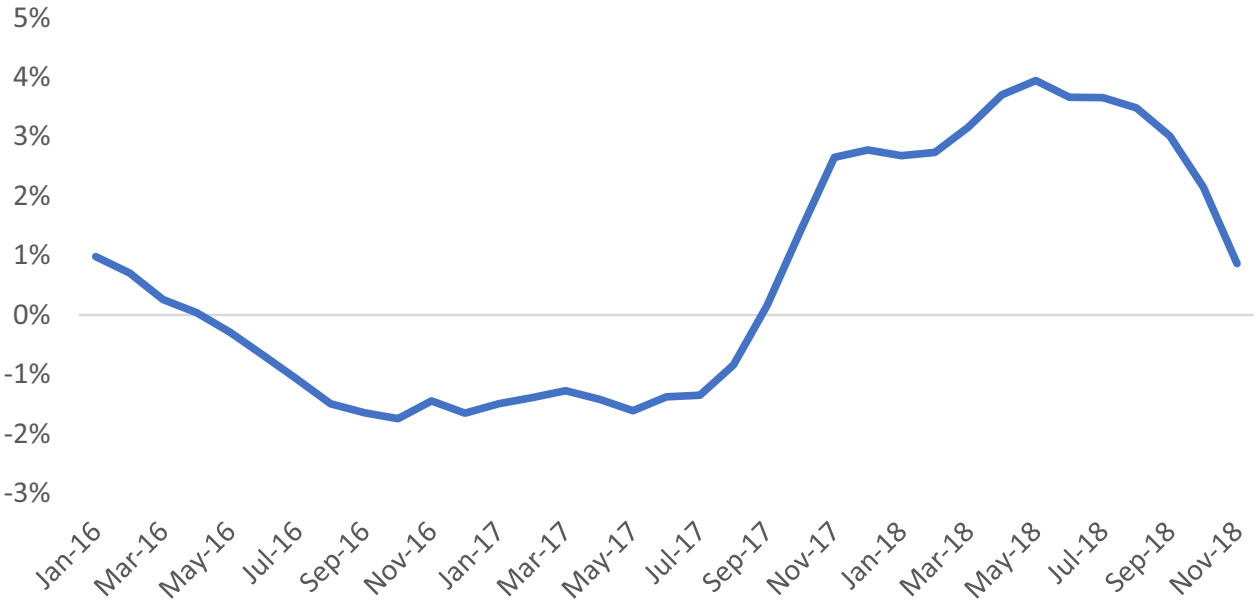

Fig. 11 Chicago SFRI

$$
\text { Chicago SFRI By Property Type }
$$

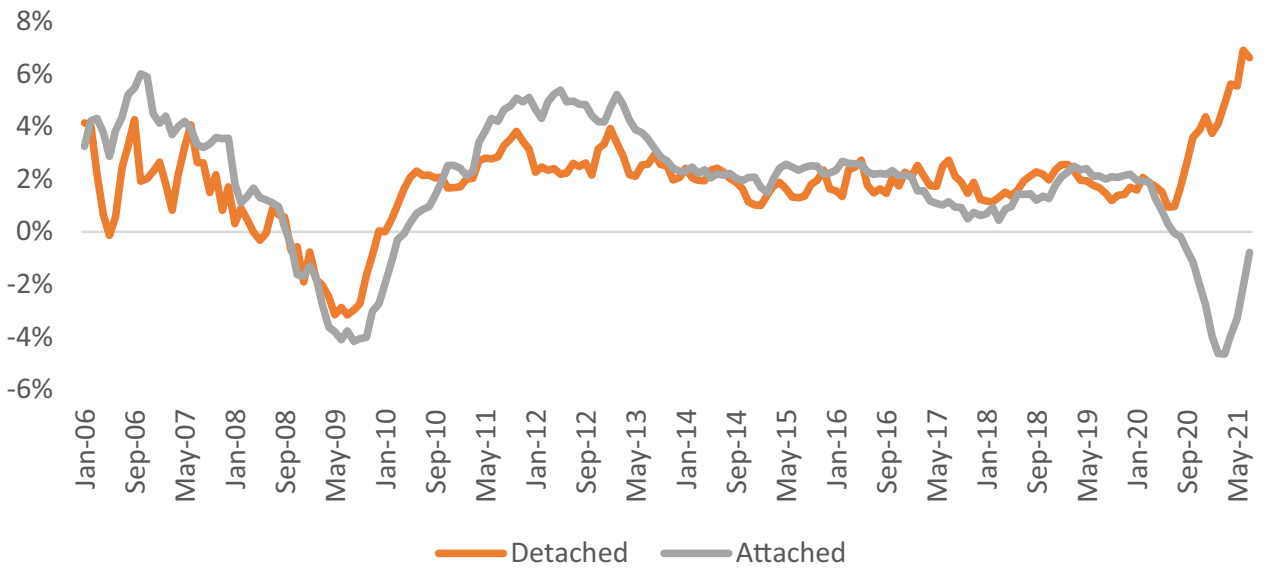


Fig. 12 SFRI in Southern California CBSAs
Year-over-year Percent Change

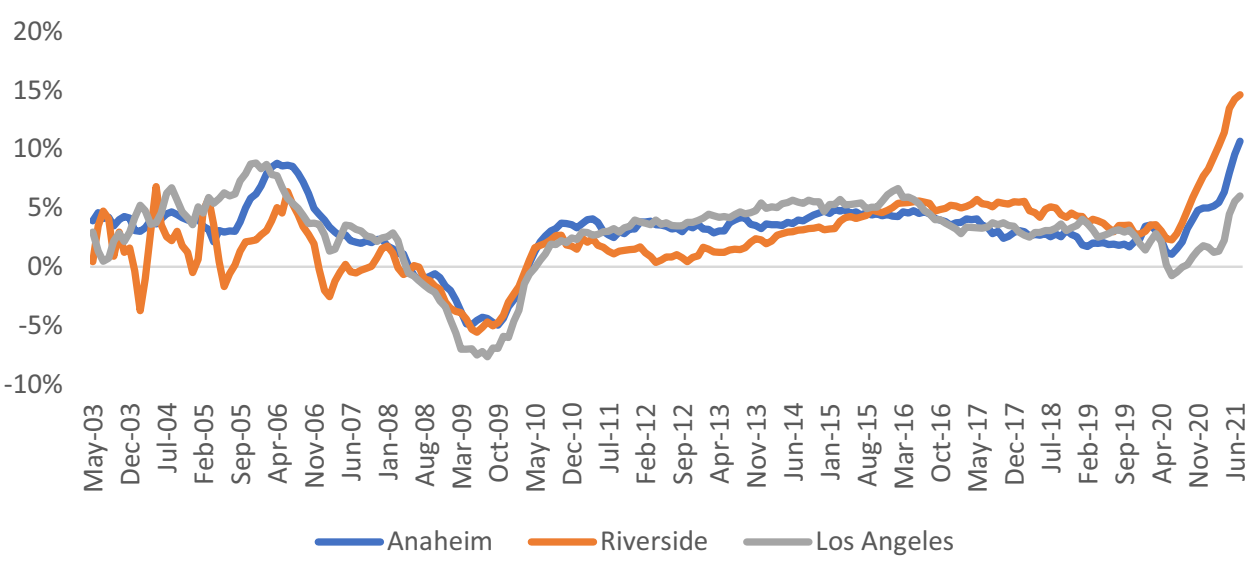

Natural hazard events impact both owner-occupied homes and the single-family rental market. In 2017, Hurricane Harvey devastated the Houston area, causing an estimated $\$ 25$ billion to $\$ 37$ billion in damages. ${ }^{11}$ Families displaced by flooding who wished to stay in the Houston area often sought out single-family rentals, driving the price of these rentals up. Prior to Hurricane Harvey, falling oil prices led to employment losses in the Houston metro and put downward pressure on rents. One month after Hurricane Harvey, rent growth in the Houston area turned positive and stayed elevated until late-2018, showing that the SFRI captures changes in the market quickly. Additionally, in the wake of a natural hazard it is important to have an accurate measure of costs facing residents of the affected areas, and the SFRI provides a measure of rental costs (Fig. 10).

Finally, as mentioned for the national index, consumer choices for structure type are evident when reviewing the SFRI for attached and detached rentals. An example of property type rents moving in different directions is the Chicago metro. The overall SFRI for Chicago shows annual decreases in rent starting in November 2020 (Fig. 11).Location choice within a metro changed during the pandemic (Kuk 2021; Liu and $\mathrm{Su} 2021$ ), with residents moving away from the center city to suburban and exurban areas. The Los Angeles metro area can be compared with Anaheim and Riverside, and these are good examples of such a shift. Rent price changes in Los Angeles and Anaheim tracked closely with each other from 2015 until 2020, when rent price changes in Anaheim outpaced Los Angeles. Rent growth in Riverside was even faster than for Los Angeles and Anaheim during the pandemic, and in July 2021 was 9 percentage points higher than Los Angeles and 4 percentage points higher than Anaheim. Such differences at a local level are important for local

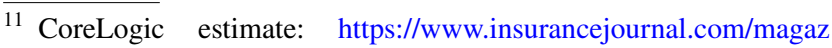
ines/mag-features/2020/07/06/574226.htm
}

governments to gauge affordability challenges for families and to ensure that areas have enough services to support families that may be struggling with increasing rent levels (Fig. 12).

\section{Implications}

Prior to the pandemic, rent growth tended to be correlated in residential housing across structure type - single-family detached, single-family attached, and multifamily. The pandemic revealed a distinct preference by households for detached houses compared with multifamily rental buildings.

The CoreLogic SFRI is unique in that it covers only the single-family rental market; it has different rent tiers based on the rent levels and property types, and it applies the repeat-pairing method to MLS data. The SFRI reflects changes in market rent and is not subject to changes to the mix of unit types rented in any given period.

We compare the SFRI with the CPI rent of primary residence and the OER at a national level and for two metropolitan areas. The SFRI leads changes in the rent of primary residence and OER and captures turning points in inflation earlier when used in place of OER in Core CPI. We observed increasing rents for higher-rent properties after the pandemic, pointing to an economic recovery that reached only higher-waged workers. Finally, we constructed property type indices, which revealed changing rent dynamics brought on by the pandemic.

Because OER represents $24 \%$ of the CPI and $30 \%$ of Core CPI, mismeasurement of OER can lead to a misunderstanding of underlying inflationary pressures in the economy. Substituting the CoreLogic SFRI for the OER in the CPI reveals that inflation emerged a full seven months earlier using the SFRI and core CPI inflation may have been understated by nearly two percentage points in mid-2021. In some urban markets, the understatement of inflation appears more 
pronounced; in the Phoenix metro area, inflation may be understated by close to 4 percentage points. Further, since OER has lagged movement in the SFRI by approximately one year, the acceleration in the SFRI in 2021 suggests that OER may accelerate in the coming year. If so, projections that the current uptick in inflation is temporary may be in jeopardy, as rising rent inflation in the CPI offsets an abatement in price pressures among other CPI components.

\section{Appendix}

The repeat sales methodology was first proposed by Bailey, Muth, and Nourse (BMN) in (1963). BMN constructed a matrix of dummy variables where the matrix takes the value of -1 if period $t$ is the period of the initial sale, or +1 if the period of the final sale and 0 otherwise for each pair of transactions. Using this, the index can be solved for with the following equation:

$\ln \left(P_{i t}\right)-\ln \left(P_{i t^{\prime}}\right)=\sum_{\tau=0}^{T} \beta_{\tau} x_{\tau i}+\varepsilon_{i}$

where $P$ is the transaction price at times $t$ and $t^{\prime}, \beta$ is the market price index at time $t$. and $\varepsilon$ is a random error term. The least squares solution is in terms of logarithms, so the index values are recovered by exponentiation.

In 1987, Case and Shiller expanded the BMN model and developed a weighted repeat sales method (WRS) by adding two new features. With housing prices increasing over time, the problem of uneven variance or heteroscedasticity was identified. Bailey et al. (1963) assumed constant variance, and the house price $\mathrm{P}_{i t}$ was modeled as a log-normal diffusion process:

$\ln P_{i t}=C_{t}-H_{i t}+N_{i t}$

where $C_{t}$ is the log of the index at time $t, H_{i t}$ is a random walk term, and $N_{i t}$ is an error term. The solution, as described in Dreiman and Pennington-Cross (2004), involved iterative steps for estimating a weighted version of the repeat sales regression and using the residuals to generate weights and repeating until convergence.

It was pointed out by Goetzmann (1992) and Shiller (1991) that the Bailey et al. (1963) repeat sales model and the Case-Shiller weighted repeat sales model both estimate the geometric mean growth rates and not the arithmetic means. This is caused by taking logarithms, then regressing, and then exponentiating the result. The exponentiation of an average of logarithms is the same as the geometric mean, and because the geometric mean of a set of numbers is bounded above by their arithmetic mean, the geometric repeat sales methods will tend to underestimate the index (Wang and Zorn (1997) give a detailed description of this issue). Goetzmann (1992) proposed a post-index correction to adjust the geometric mean using the estimate of the variance in house price growth to approximate the arithmetic mean.

The empirical model used to estimate the SFRI was developed by Shiller (1991). It is a reformulation of prior repeat pairs methodologies discussed above. Shiller's reformulation of the regression model avoids the need for exponentiation of the regression index results and, therefore, maintains an arithmetic formulation.

As opposed to Bailey et al. (1963), the matrix of constructed dummy variables described above in Eq. (1) is replaced by a matrix of prices where the $-1 \mathrm{~s}$ in the former matrix are replaced by minus the initial price and the $1 \mathrm{~s}$ in the former matrix are replaced by the second sale price. Additionally, the dependent variable is structured as the price of the first sale if sold in the first period, zero otherwise. This model structure yields reciprocal price indices that can be inverted to yield an arithmetic index directly. This is also a value weighted technique in that the index value in period $t$ is the average of the sales transactions in the $t$ th period divided by the average of all property values in the base period. Averages for all positive values (sale transaction prices are never negative) are more influenced by larger values than smaller values.

\section{References}

Ambrose, Brent W., N. Edward Coulson, and Jiro Yoshida. 2015. The Repeat Rent Index. Review of Economics and Statistics 97 (5): 939-950.

Bailey, Martin J., Richard F. Muth, and Hugh O. Nourse. 1963. A Regression Method for Real Estate Price Index Construction. Journal of the American Statistical Association 58: 933-942.

Bernstein, Jared, Ernie Tedeschi, and Sarah Robinson. 2021. Housing Prices and Inflation. Whitehouse.gov, https://www.whitehouse. gov/cea/blog/2021/09/09/housing-prices-and-inflation/

Bolton Smith, Maiclaire. 2020. Understanding Risk in a Decade of Natural Catastrophes. Insurance Journal, https://www.insurancej ournal.com/magazines/mag-features/2020/07/06/574226.htm

Bureau of Economic Analysis. 2020. Overview of Source Data and Estimating Methods, Chapter 5: Personal Consumption Expenditures. NIPA Handbook of Concepts and Methods. https://www. bea.gov/resources/methodologies/nipa-handbook/pdf/chapter-05. pdf.

Bureau of Labor Statistics. 2009 How the CPI measures price change of Owners' equivalent rent of primary residence (OER) and Rent of primary residence (Rent). https://www.bls.gov/cpi/factsheets/ owners-equivalent-rent-and-rent.pdf

Bureau of Labor Statistics. 2015. The Consumer Price Index, in $B L S$ Handbook of Methods. https://www.bls.gov/opub/hom/cpi/pdf/ cpi.pdf.

Case, Karl E., and Robert J. Shiller. 1987. Prices of single-family homes since 1970: new indexes for four cities. New England Economic Review Sept./Oct.: 45-56. 
Chen, Shu. 2021. Rent Growth Diverged Across Property Type During Pandemic. CoreLogic.com. https://www.corelogic.com/intel ligence/find-stories/rent-growth-diverged-across-property-typeduring-pandemic/

Crone, Theodore, Leonard Nakamura, and Richard Voith. 2006. The CPI For Rents: A Case of Understated Inflation. Federal Reserve Bank of Philadelphia Working Paper No. 06-7.

Delventhal, Matthew J. and Andrii Parkhomenko. 2021. Spatial Implications of Telecommuting. https://papers.ssrn.com/sol3/papers. cfm?abstract_id=3746555.

Deng, Yongheng, Stuart A. Gabriel, and Frank E. Nothaft. 2003. Duration of Residence in the Rental Housing Market. Journal of Real Estate Finance and Economics 26 (2/3): 267-285.

Dreiman, Michelle H., and Anthony Pennington-Cross. 2004. Alternative Methods of Increasing the Precision of Weighted Repeat Sales House Prices Indices. The Journal of Real Estate Finance and Economics 28 (4): 299-317.

Goetzmann, William. 1992. The Accuracy of Real Estate Indexes: Repeat Sales Estimators. Journal of Real Estate Finance and Economics 5: 5-53.

Joint Center for Housing Studies of Harvard University. 2016. The State of the Nation's Housing 2016. https://www.jchs.harvard.edu/resea rch-areas/reports/state-nations-housing-2016.

Kuk, John, Ariela Schachter, Jacob William Faber, and Max Besbris. 2021. The COVID-19 Pandemic and the Rental Market: Evidence from Craigslist. American Behavioral Scientist I-26.

Liu, Sitian, and Yicken Su. 2021, The Impact of the COVID-19 Pandemic on the Demand for Density: Evidence from the U. S. Housing Market. https://yichensu.files.wordpress.com/2021/04/liusu_ covid_4_11_21.pdf.

Nothaft, Frank E. 2018. Single-Family Rental: Measuring Rent Growth and Return. Journal of the Center for Real Estate Studies 6 (1): $5-14$.

Ozimek, Adam. 2016. Why Inflation Didn't Slow Much During the Great Recession. https://www.economy.com/dismal/analysis/ datapoints/284051/Why-Inflation-Didnt-Slow-Much-Duringthe-Great-Recession/

Ramani, Arjun and Nicholas Bloom. 2021. The Donut Effect of COVID-19 on Cities. NBER Working Paper No. 28876.

Rappaport, Jordan. 2021. Hybrid Officing Will Shift Where People and Businesses Decide to Locate. Federal Reserve Bank of Kansas City Economic Bulletin.

S\&P Dow Jones Indices. 2021. S\&P Case-Shiller Home Price Indices Methodology. https://www.spglobal.com/spdji/en/documents/ methodologies/methodology-sp-corelogic-cs-home-price-indic es.pdf.

Shiller, Robert J. 1991. Arithmetic Repeat Sales Price Estimators. Journal of Housing Economics 1: 110-126.

Stanton, Christopher T. and Pratyush Tiwari. 2021. Housing Consumption and the Cost of Remote Work. NBER Working Paper No. 28483.

Wang, Ferdinand T., and Peter M. Zorn. 1997. Estimating House Price Growth with Repeat Sales Data: What's the Aim of the Game? Journal of Housing Economics 6: 93-118.
Publisher's Note Springer Nature remains neutral with regard to jurisdictional claims in published maps and institutional affiliations.

Molly Boesel holds the position of Principal Economist in the Office of the Chief Economist at CoreLogic, where she is responsible for analyzing and forecasting housing and mortgage market trends, including the single-family rental market. She has more than 20 years experience in mortgage market analysis, model development, and risk analysis in the housing finance industry. Molly previously worked at both Fannie Mae and Freddie Mac, where she focused on market forecasts and risk management. She holds a B.S. in Economics from James Madison University and an M.S. in Consumer Economics and Housing from Cornell University. She was named as one of the 2017 Women of Influence by Housing Wire Magazine and has served as chair for the National Association for Business Economics Real Estate/Construction Roundtable since 2019.

Shu Chen holds the position of senior professional, statistical analysis, as part of the Office of the Chief Economist at CoreLogic. She works with senior economists to provide insights for multiple listing service data and the single-family rent index. Prior to CoreLogic, Chen was a contributor to the consumer expenditure survey program for the Bureau of Labor Statistics, and the credit risk and analytics team at Fannie Mae. She received her undergraduate degree in Mathematics and Computer Science from Fuzhou University in China, and a master's degree in statistics from the University of Virginia.

Frank E. Nothaft is chief economist for CoreLogic, America's largest provider of advanced property and ownership informationanalytics and data-enabled services. He leads the economics team responsible for analysis, commentary and forecasting in global real estate, insurance, and mortgage markets. Before joining CoreLogic Frank served as Vice President and Chief Economist at Freddie Mac. Prior to Freddie Mac, he was an economist with the Board of Governors of the Federal Reserve System in the mortgage and consumer finance section and served as assistant to Governor Henry C. Wallich. Frank is a Certified Business Economist (@), a National Association for Business Economics (NABE) Fellow, and received the NABE Outlook Award for 2018. $\mathrm{He}$ has served as president of the American Real Estate and Urban Economics Association, board member of NABE and the Financial Management Association, Advisory Board member of the Real Estate Research Institute, Editorial Board member of the Journal of Real Estate Finance and Economics, and is a Weimer School Fellow of the Homer Hoyt Institute. Frank graduated from New York University with a B.A. in mathematics and computer science and holds a Ph.D. in economics from Columbia University. 